\title{
A Proteomic Network for Symbiotic Nitrogen Fixation Efficiency in Bradyrhizobium elkanii
}

\author{
Bret Cooper, ${ }^{1,+}$ Kimberly B. Campbell, ${ }^{1}$ Hunter S. Beard, ${ }^{1}$ Wesley M. Garrett, ${ }^{2}$ Joseph Mowery, ${ }^{1}$ \\ Gary R. Bauchan, ${ }^{1}$ and Patrick Elia ${ }^{1}$ \\ ${ }^{1}$ Soybean Genomics and Improvement Laboratory, USDA-ARS, Beltsville, MD 20705, U.S.A.; and ${ }^{2}$ Animal Biosciences and \\ Biotechnology Laboratory, USDA-ARS
}

Accepted 7 November 2017.

\begin{abstract}
Rhizobia colonize legumes and reduce $\mathrm{N}_{2}$ to $\mathrm{NH}_{3}$ in root nodules. The current model is that symbiotic rhizobia bacteroids avoid assimilating this $\mathrm{NH}_{3}$. Instead, host legume cells form glutamine from $\mathrm{NH}_{3}$, and the nitrogen is returned to the bacteroid as dicarboxylates, peptides, and amino acids. In soybean cells surrounding bacteroids, glutamine also is converted to ureides. One problem for soybean cultivation is inefficiency in symbiotic $\mathrm{N}_{2}$ fixation, the biochemical basis of which is unknown. Here, the proteomes of bacteroids of Bradyrhizobium elkanii USDA76 isolated from $\mathrm{N}_{2}$ fixation-efficient Peking and -inefficient Williams 82 soybean nodules were analyzed by mass spectrometry. Nearly half of the encoded bacterial proteins were quantified. Efficient bacteroids produced greater amounts of enzymes to form Nod factors and had increased amounts of signaling proteins, transporters, and enzymes needed to generate ATP to power nitrogenase and to acquire resources. Parallel investigation of nodule proteins revealed that Peking had no significantly greater accumulation of enzymes needed to assimilate $\mathrm{NH}_{3}$ than Williams 82. Instead, efficient bacteroids had increased amounts of enzymes to produce amino acids, including glutamine, and to form ureide precursors. These results support a model for efficient symbiotic $\mathrm{N}_{2}$ fixation in soybean where the bacteroid assimilates $\mathrm{NH}_{3}$ for itself.
\end{abstract}

Rhizobia are soil bacteria that can establish symbiosis in root nodules of legumes. In nodules, rhizobia bacteroids reduce (fix) atmospheric $\mathrm{N}_{2}$ for the legume in exchange for protection and carbon (C), a molecular building block and reductant for energy (Udvardi and Poole 2013). Symbiosis begins when rhizobia recognize root flavonoids and secrete lipochitooligosaccharides (Dénarié et al. 1996). In Medicago truncatula, a model legume, mobile plant peptides are then returned to the bacteroid to establish and maintain symbiosis (Farkas et al. 2014). The peptides can be cultivar-specific; thus, there are genetic determinants that dictate cultivar and rhizobia strain relationships. For soybeans, the most cultivated legume in the world, similar peptides have not yet been found, but there are preferences for $\mathrm{N}_{2}$-fixing Bradyrhizobium spp., and this implies that there are genetic determinants in soybean that dictate strain compatibility (Terpolilli

${ }^{\dagger}$ Corresponding author: Bret Cooper; E-mail: bret.cooper@ars.usda.gov

*The $\boldsymbol{e}$-Xtra logo stands for "electronic extra" and indicates that five supplementary figures and one supplementary dataset are published online.

This article is in the public domain and not copyrightable. It may be freely reprinted with customary crediting of the source. The American Phytopathological Society, 2018. et al. 2012). This specificity allows selection for efficiency among the multitudes of strains in the soil, but inefficiency pervades because not all soils are naturally inhabited by the mostcompatible strains and some inefficient fixers can be more aggressive nodulators (Sessitsch et al. 2002).

Rhizobia that sufficiently nodulate but fail to support $\mathrm{N}_{2}$ fixation are designated $\mathrm{Nod}^{+} \mathrm{Fix}^{-}$(Wilson et al. 1987). The descriptions of Fix ${ }^{-}$mutants underpin the basic theory of symbiotic $\mathrm{N}_{2}$ fixation. Fixation proceeds in the bacteroid when $\mathrm{O}_{2}$ is buffered by leghemoglobin, the most abundant legume protein in surrounding legume cells. The lowered $\mathrm{O}_{2}$ concentrations stimulate the bacteroid FixL-FixJ two-component system that regulates downstream processes essential to $\mathrm{N}_{2}$ fixation. Bacteroid nitrogenase then reduces atmospheric $\mathrm{N}_{2}$ to $\mathrm{NH}_{3}$, a process that requires ample ATP generated by a special high-affinity oxidase for the low- $\mathrm{O}_{2}$ environment. To produce this ATP, the bacteroids receive $\mathrm{C}$ from the legume in the form of dicarboxylic acids, and they also receive essential iron, sulfur, molybdenum, phosphate, and other molecules, such as branched-chain amino acids. In exchange, the bacteroid produces $\mathrm{NH}_{3}$, which (apparently) diffuses across the bacteroid membrane and is transported as $\mathrm{NH}_{4}^{+}$across the legume symbiosome membrane. Legume cells then assimilate $\mathrm{NH}_{4}^{+} / \mathrm{NH}_{3}$ into glutamate by the legume glutamine synthetase and glutamate synthase enzymes operating in a regulated cycle. These principles have been reviewed by Vance and Gantt (1992), Dénarié et al. (1996), Patriarca et al. (2002), Sessitsch et al. (2002), Terpolilli et al. (2012), Udvardi and Poole (2013), and Downie (2014).

Rhizobium Fix ${ }^{-}$mutants define specific molecular processes of $\mathrm{N}_{2}$ fixation, but the network of the entire system is mostly inferred from the single nodes described by individual mutants. No molecular systems-level picture of $\mathrm{N}_{2}$ fixation efficiency exists for a bacteroid. Reaching toward our goal of understanding $\mathrm{N}_{2}$ fixation efficiency, we have studied a single isolate of soybean symbiont B. elkanii USDA 76 (Be76) in two different hosts. Be76 nodulates $\left(\mathrm{Nod}^{+}\right)$soybean cultivars Peking and Williams 82 (W82) but fixes $\mathrm{N}_{2}$ more efficiently in Peking. Hence, cultivar specificity rather than bacterial mutation allows us to evaluate $\mathrm{Fix}^{+} / \mathrm{Fix}^{-}$ phenotypes. Here, we have used mass spectrometry to estimate the amounts of 3,713 of the 8,362 proteins encoded by the Be76 genome (Reeve et al. 2017). We used this data to resolve enzymatic pathways that explain Be76 biochemistry. The results support a model for symbiotic $\mathrm{N}_{2}$ fixation efficiency that is substantially different than what has been proposed for other rhizobia in other legumes.

\section{RESULTS}

Fix $^{+} /$Fix $^{-}$phenotypes.

G. max cv. Peking and W82 control seedlings were grown without Be76 and without supplemental nitrogen fertilizer. After 
6 weeks, both W82 and Peking untreated controls were equally stunted and yellow (Fig. 1A). This indicated that the potting substrate was nitrogen-poor and free of contaminating rhizobia. When the seedlings were inoculated with Be76, there were profound effects on soybean growth, although the two soybean cultivars responded differently. Be76-treated Peking plants developed lush, dark green leaves, signs of sufficient symbiotic $\mathrm{N}_{2}$ fixation (Fig. 1A). By contrast, the upper leaves of Be76-treated W82 showed the yellowness of nitrogen deficiency at 6 weeks after inoculation (Fig. 1A). Nodulation occurred on treated roots for both W82 and Peking, indicating that each plant received a nodulation signal from Be76, communicated with Be76, and allowed and supported symbiosis (Fig. 1B). Nodules on W82 roots, however, were more numerous than on Peking (Fig. 1B), agreeing with observations that $\mathrm{Fix}^{-}$strains nodulate more often (Hirsch and Smith 1987). Dissected nodules from each plant showed evidence of leghemoglobin production, but W82 nodules had slightly thicker cortexes and smaller red centers (Fig. 1C). We attempted to determine whether nodules from Peking and W82 hosted different numbers of bacteroids by counting purified bacteroids with a hemocytometer. There was an order of $10^{8}$ bacteroids recovered per nodule for both W82 and Peking. Nodules are estimated to host $10^{9}$ bacteroids (Bergersen 1997), so our inability to recover $100 \%$ of bacteroids made it difficult to assess whether any nodule hosted significantly more bacteroids. Nevertheless, through these efforts we noticed that bacteroids from W82 appeared to be slightly larger and elongated, although no statistical measurement was performed to confirm this observation (Fig. 1D through G). All together, these results define symbiotic $\mathrm{N}_{2}$ fixation deficiency for Be76 in W82 (Fix ${ }^{-}$) and symbiotic $\mathrm{N}_{2}$ fixation efficiency for Be76 in Peking (Fix ${ }^{+}$).

\section{Protein quantitation overview.}

We prepared peptides from Be76 bacteroids from Peking and W82, labeled and loaded equivalent amounts for mass spectrometry analysis, and assessed increasing and decreasing relative protein accumulation (amount) changes, using tandem mass tag (TMT) chemical quantitation (Isasa et al. 2015). We also evaluated relative protein abundances as a percentage of all proteins found through normalized spectral abundance factors (NSAF) (Paoletti et al. 2006). There were 3,713 Be76 proteins evaluated by TMT, 1,305 of which had significant changes in accumulation. Although bacteroids were extensively washed and filtered, 1,175 soybean proteins were also detected. This is explained by the physical associations bacteroids have with soybean proteins and by the sensitivity of the mass spectrometer. Despite the identification of soybean proteins at a 1 to 3 ratio, NSAF analysis, which accounts for the numbers of mass
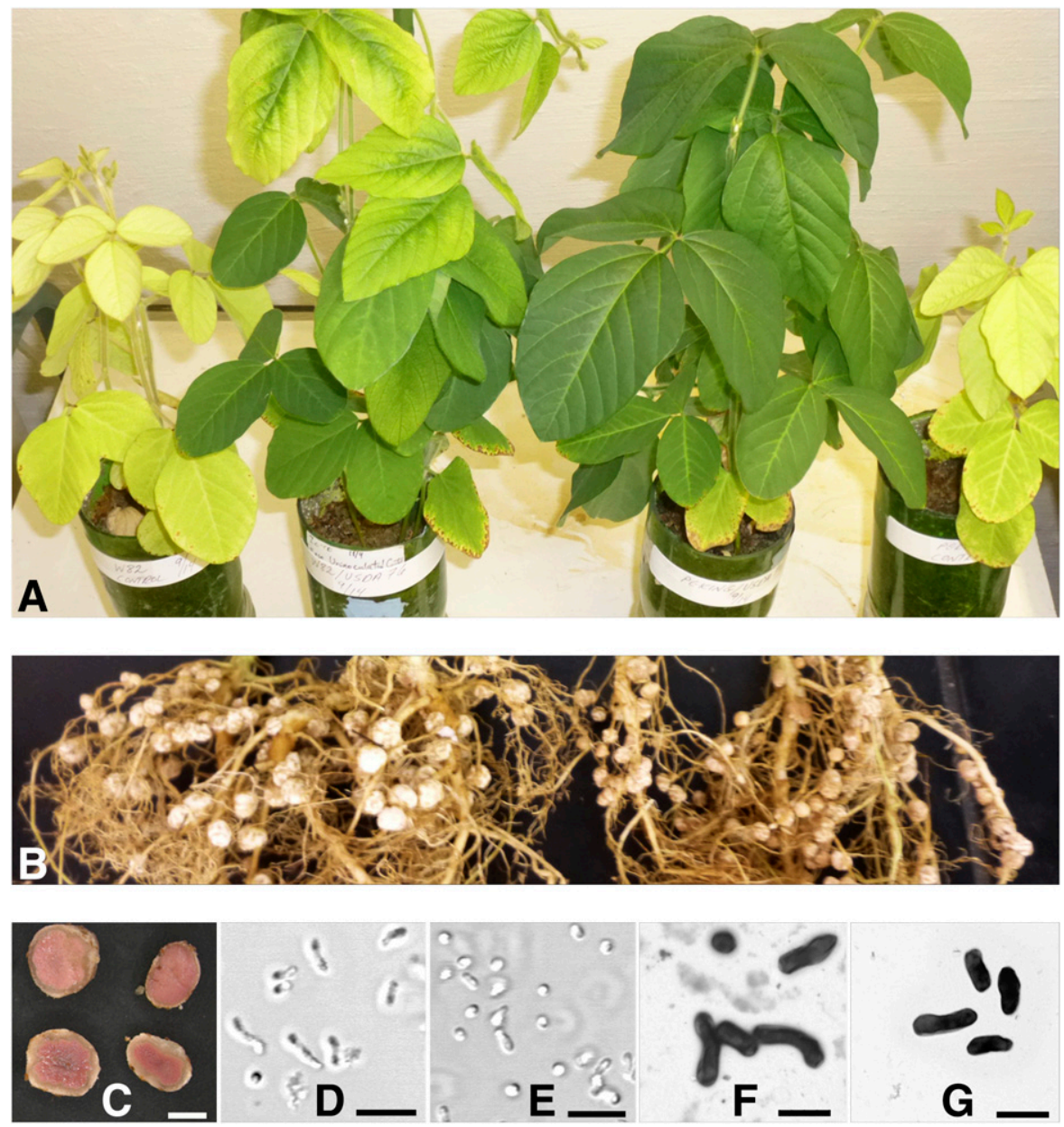

Fig. 1. Phenotypes of symbiotic $\mathrm{N}_{2}$ fixation for Bradyrhizobium elkanii USDA 76 (Be76) in Glycine max cv. Williams 82 (W82) and Peking 6 weeks after inoculation. A, From left to right: W82 control (no Be76) with severe nitrogen deficiency, W82/Be76 with inefficient $\mathrm{N}_{2}$ fixation, Peking/Be76 with efficient $\mathrm{N}_{2}$ fixation, and Peking control (no Be76) with severe nitrogen deficiency. B, More abundant and larger nodules on W82 roots (left) versus Peking (right). C, Thicker cortexes of nodules from W82 (bottom) versus Peking (top). Bar is $2 \mathrm{~mm}$. D, Be76 bacteroids from W82 (differential interference contrast microscopy, bar is $5 \mu \mathrm{m}$ ). E, Be76 bacteroids from Peking (differential interference contrast microscopy, bar is $5 \mu \mathrm{m}$ ) (note the shorter bacteroids compared with those seen in D). F, Uranyl acetate-stained Be76 bacteroids from W82 (transmission electron microscopy, bar is $2 \mu \mathrm{m}$ ). G, Uranyl acetate-stained Be 76 bacteroids from Peking (transmission electron microscopy, bar is $2 \mu \mathrm{m}$ ) (note the shorter bacteroids compared with those seen in F). 
spectra matched to proteins, revealed that Be76 proteins comprised $92 \%$ of the NSAF totals, meaning that soybean proteins represented only a small fraction of our bacteroid preparations. Pearson correlation clustering of Be76 TMT quantitative values revealed the reproducibility of the experiments (Fig. 2A). The $\log _{2}$ fold changes for all Be76 proteins exhibited a normal distribution, with a mean between 0.1 and 0.2 (Fig. 2B), that was shifted from zero because there were 3.8 times as many Be76 proteins from Peking with significantly increased amounts as proteins with decreased amounts (Fig. 2C). Generally, the overall data show that Be76 responded to Peking differently than to W82 and that some Be76 proteins, but not all, were differentially regulated.

\section{Nod signaling.}

In Be76 bacteroids from Peking, there were increased amounts of 36 enzymes that can catalyze the production of lipochitooligosaccharide signals. These proteins included NodN, NolO, and FabG (NodG functional ortholog [Mao et al.
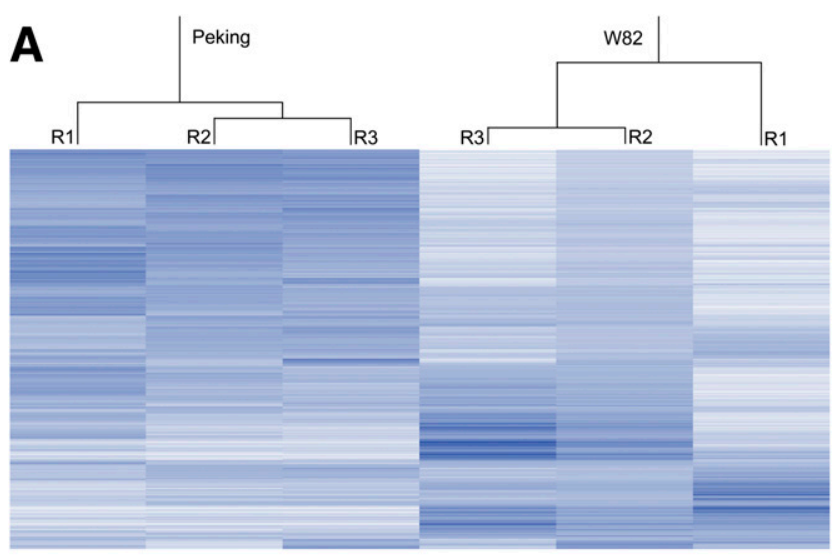

B

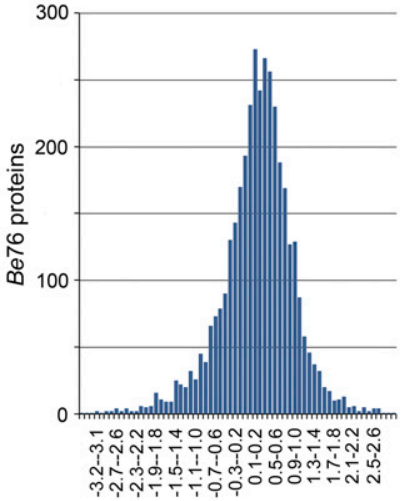

$\log _{2}$ fold av. Peking/W82
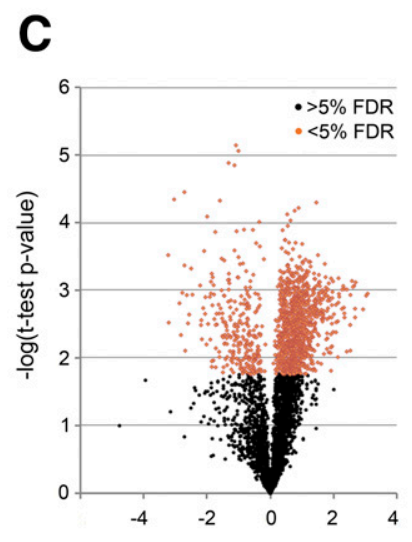

$\log _{2}$ fold av. Peking/W82
Fig. 2. Hierarchical clustering and statistical representation of quantitative data for proteins from Bradyrhizobium elkanii USDA 76 (Be76) from Peking and Glycine max cv. Williams 82 (W82). A, Clustering of the normalized and scaled tandem mass tag (TMT) reporter ion $\mathrm{S} / \mathrm{N}$ values for three biological replicate $(\mathrm{R})$ samples of $\mathrm{Be} 76$ from Peking and three biological replicate samples of Be76 from W82. Blue is the highest amount of relative expression and white is the lowest. Clustering was performed with Treeview 3.0. B, Distribution of $\log _{2}$ average of normalized and scaled TMT reporter ion S/N values for proteins from $\mathrm{Be} 76$ from Peking divided by the same for $\mathrm{Be} 76$ from W82. Bins are increments of 0.1. C, Volcano distribution of $\log _{2}$ average normalized and scaled TMT reporter ion $\mathrm{S} / \mathrm{N}$ values for proteins from Be76 from Peking divided by the same for Be76 from W82 versus the $-\log (t$ test $P$ value) for each set of reporter ion $\mathrm{S} / \mathrm{N}$ values for each protein. Proteins with $P$ values with $\leq 5 \%$ false discovery rate (FDR) are in orange and those with $>5 \%$ FDR are in black.
2016]) (Table 1). Several of these proteins were among the top 20 proteins with the greatest changes in accumulation between Peking and W82 (Supplementary Dataset S1). Many of these proteins were assigned to known enzymatic pathways, in the Kyoto Encyclopedia of Genes and Genomes (KEGG) database, for amino sugar metabolism and lipopolysaccharide biosynthesis (Supplementary Fig. S1). These pathways lead to the production of Nod factors, and the results imply that Be76 is enzymatically capable of forming complex molecular signals to maintain an efficient symbiotic relationship in Peking.

\section{$\mathbf{N}_{2}$ fixation.}

It could be presumed that $\mathrm{N}_{2}$ fixation efficiency in Peking is a product of increased amounts of nitrogenase in Be76. There were, however, no statistically different changes in the accumulations of nitrogenase proteins (NifB, NifD, NifE, NifH, NifK, NifN, NifQ, NifS, NifU), nitrogenase gene regulation and stability proteins (NifA, NifW), or other proteins required for $\mathrm{N}_{2}$ fixation (FixA, FixB, FixC, FixG, FixR, FixU, FixX). There were, however, increased amounts of transport systems for iron, sulfur, and molybdenum, essential cofactors of $\mathrm{N}_{2}$ fixation enzymes.

Nitrogenase is powered by ATP, but there were no significant increases in Be76 enzymes from Peking needed to complete the canonic citric acid (tricarboxylic acid [TCA]) cycle to produce NADH (Fig. 3). There was, however, an additional pathway for an NADH shunt that emerged for Be76 from Peking (Prell et al. 2009a). When ${ }^{14} \mathrm{C}$-malate is supplied to B. japonicum bacteroids, glutamate is the primary destination for ${ }^{14} \mathrm{C}$, meaning that 2-oxoglutarate is used by Be76 glutamate synthase (GltB/D) for glutamate formation (Salminen and Streeter 1990). Consequently, a redirection of 2-oxoglutarate has the potential to short-circuit the TCA cycle. This $\mathrm{C}$ loss can be solved through the additional supply of gamma aminobutyric acid (GABA), a viable $\mathrm{C}$ source that is likely supplied by soybean (Prell et al. 2009a; Salminen and Streeter 1990). Indeed, we observed increased amounts of GABA oxoglutarate aminotransferase (GabT) to break down GABA. The breakdown of GABA also produces succinic semialdehyde, leading to succinate and NADH to complete the shunt. In essence, Be76 from Peking was enzymatically geared to produce NADH via the shunt, and there were increased amounts of NADH dehydrogenase, a high-affinity cbb3-type cytochrome c oxidase (FixP) crucial for the low-oxygen environment required by nitrogenase, and F-type ATPase to produce ATP by oxidative phosphorylation (Fig. 3; Supplementary Fig. S2). These data reveal increased amounts of enzymes leading to the production of ATP needed to power $\mathrm{N}_{2}$ fixation.

The induction of $\mathrm{N}_{2}$ fixation occurs when leghemoglobin lowers $\mathrm{O}_{2}$ at the symbiosomes in the nodule. The globin subunits of leghemoglobin are produced by the plant, but its hemebinding porphyrin ring is produced by the bacteroid (Hu et al. 2008). In Be76 from Peking, there were increased amounts of enzymes in the pathway for the construction of porphyrins. Necessarily, there were increased amounts of iron and heme transport proteins, the substrates of which are needed for the assembly of that cofactor, and there were increased amounts of NifX, the cofactor processing protein.

As $\mathrm{O}_{2}$ is lowered, FixL phosphorylates FixJ, which activates $F_{i x K_{2}}$, a regulator of FixNOPQ and FixGHIS, which are required for $\mathrm{N}_{2}$ fixation (Nellen-Anthamatten et al. 1998; Sciotti et al. 2003). Our study revealed increased accumulation of FixJ homologs in Be76 from Peking (Table 2). FixJ signaling can explain the observed increases of FixP and FixH. There also may be alternative routes of regulation, possibly through separate two-component systems like the RegA-related WP_018269164.1 
or through additional response regulators like Fnr family protein WP_016847231.1, all of which had increased accumulation as well (Table 2). FixL-FixJ may control larger molecular networks including amino acid metabolism, polyhydroxybutyrate polymerization, and other processes described below that had increased amounts of enzymes in their respective pathways (Bobik et al. 2006; Mesa et al. 2009). Together, these data show increased amounts of proteins involved in signaling for $\mathrm{N}_{2}$ fixation in Be76 from Peking.

\section{Carbon metabolism.}

Dicarboxylic acids, namely malate, are a primary source of $\mathrm{C}$ provided by soybean to B. japonicum (Salminen and Streeter 1987; Udvardi et al. 1988). The bacteroid converts malate to pyruvate with NAD-dependent malic enzymes (Dao et al. 2008). In Be76 from Peking, two malic enzymes had increased accumulation (Fig. 3). There also were increases in other pyruvate-forming enzymes such as pyruvate kinase and alanine-glyoxylate transaminase. The increased amounts of these enzymes could lead to increased pools of pyruvate, a precursor to acetyl CoA for the TCA cycle discussed above but, also, a precursor for biosynthesis of branched-chain leucine, isoleucine, and valine (LIV) and alanine, amino acids that will be discussed later (Supplementary Fig. S3).

In Rhizobium leguminosarum, dicarboxylic acids like malate are perceived and regulated by the two-component DctBDctD and transported through DctA (Reid and Poole 1998). A complementary two-component DctS-DctR with a DctP transporter also exists. In Be76, we identified 10 DctB/D and
DctA/P homologs, but none exhibited significantly increased accumulation in Peking. Thus, dicarboxylate acquisition may not drive efficiency. By contrast, five of 11 sugar/glycerol transport-binding proteins increased. While evidence suggests that sucrose is not a critical C source for B. japonicum (Terpolilli et al. 2012; Udvardi et al. 1990), other $C$ substrates besides malate can be used for fuel (Glenn and Dilworth 1981; Price et al. 1987; Ruiz-Argüeso et al. 1979). There were increased amounts of enzymes to convert formate, formaldehyde, and formamide to $\mathrm{CO}_{2}$, which can be used to form oxaloacetate to feed the TCA cycle, and there were increased amounts of enzymes to convert starch to glucose-6-P, mannose to fructose 6-P, and GABA to succinic semialdehyde (Fig. 3). Thus, these data show that Be76 from Peking had increased enzymatic capabilities to utilize multiple $\mathrm{C}$ inputs. To this end, Be76, capable of photosynthesis as free-living soil bacterium, decreased its Rubisco accumulation in the darkness of the nodule as Peking provided $\mathrm{C}$ resources (Fig. 3).

\section{Amino acid metabolism.}

Rhizobia also can use amino acids as $\mathrm{C}$ sources in vitro, and it is known that $R$. leguminosarum requires LIV amino acids provided by peas to maintain symbiosis (Prell et al. 2009b). Interestingly, more plentiful than dicarboxylic acid and sugar transporter proteins were membrane amino acid permeases and amino acid substrate-binding proteins, 26 of which had increased accumulation in Be76 from Peking (Table 3). These included homologs of solute-binding proteins BraC and AapJ, and ATP-binding proteins BraF, BraG, and AapP, which are required

Table 1. Accumulation change (Peking/Glycine max cv. Williams 82 [W82]) and normalized spectral abundance factors (NSAF) of Bradyrhizobium elkanii USDA 76 (Be76) proteins for Nod factor production

\begin{tabular}{|c|c|c|c|}
\hline Record & NSAF $^{\mathbf{a}}$ & $\log _{2}$ fold change & Annotation \\
\hline WP_018273240.1 & 0.013 & 2.7 & $N$-acetylgalactosamine-6-sulfatase \\
\hline WP_016840512.1 & 0.019 & 2.5 & Arylsulfatase \\
\hline WP_026192276.1 & 0.005 & 2.2 & Arylsulfatase \\
\hline WP 018268983.1 & 0.006 & 2.1 & Sulfatase-modifying factor \\
\hline WP_018273584.1 & 0.004 & 2.1 & Arylsulfatase \\
\hline WP_016846903.1 & 0.019 & 2.0 & Arylsulfatase \\
\hline WP_016839856.1 & 0.021 & 2.0 & Nodulate formation efficiency $\mathrm{C}$ \\
\hline WP_016845251.1 & 0.006 & 2.0 & Efem/EfeO family lipoprotein \\
\hline WP_018272004.1 & 0.004 & 1.7 & Lytic transglycolase \\
\hline WP_018271504.1 & 0.009 & 1.3 & Carbamoyltransferase; NolO \\
\hline WP 026192273.1 & 0.016 & 1.3 & $\mathrm{~N}$-acetylgalactosamine-6-sulfatase \\
\hline WP_018272686.1 & 0.010 & 1.3 & Lipopolysaccharide core biosynthesis glycosyltransferase \\
\hline WP 016842739.1 & 0.033 & 1.3 & Phosphoglucosamine mutase \\
\hline WP_016845858.1 & 0.024 & 1.3 & $\mathrm{FabG}$ \\
\hline WP 016843727.1 & 0.009 & 1.2 & Lytic transglycosylase \\
\hline WP_016844779.1 & 0.005 & 1.1 & UDP-glycosyltransferase \\
\hline WP_018272223.1 & 0.014 & 1.1 & Membrane-bound lytic murein transglycosylase \\
\hline WP_026192693.1 & 0.016 & 1.0 & FabG \\
\hline WP_050994123.1 & 0.004 & 1.0 & Succinoglycan biosynthesis protein \\
\hline WP_026192272.1 & 0.008 & 1.0 & Membrane-bound lytic murein transglycosylase \\
\hline WP_026193328.1 & 0.007 & 1.0 & $1,4-\beta$-mannosyl- $N$-acetylglucosamine phosphorylase \\
\hline WP 016846482.1 & 0.005 & 1.0 & NodN \\
\hline WP_018271538.1 & 0.045 & 0.9 & Membrane-bound lytic murein transglycosylase \\
\hline WP 018271101.1 & 0.003 & 0.9 & Lauroyl acyltransferase \\
\hline WP_026192171.1 & 0.022 & 0.9 & 3-deoxy-manno-octulosonate cytidylyltransferase \\
\hline WP_026191813.1 & 0.008 & 0.9 & UDP- $N$-acetylmuramoylalanine-D-glutamate ligase \\
\hline WP_016845103.1 & 0.004 & 0.7 & $S$-adenosylmethionine-dependent methyltransferase \\
\hline WP_026192034.1 & 0.024 & 0.7 & Mannose-1-phosphate guanylyltransferase \\
\hline WP_026192162.1 & 0.012 & 0.7 & Peptidoglycan-binding protein \\
\hline WP_018269887.1 & 0.023 & 0.7 & GDP-mannose 4,6-dehydratase \\
\hline WP_041482614.1 & 0.004 & 0.7 & 3-Deoxy-D-manno-octulosonic acid transferase \\
\hline WP_016844239.1 & 0.006 & 0.7 & Polysaccharide biosynthesis protein \\
\hline WP 038376422.1 & 0.018 & 0.7 & Peptide $N$-acetyl-glucosaminyltransferase \\
\hline WP_018270081.1 & 0.025 & 0.7 & Peptidoglycan- $N$-acetyl-glucosamine deacetylase \\
\hline WP 018269634.1 & 0.011 & 0.6 & Membrane-bound lytic murein transglycosylase \\
\hline WP_016845818.1 & 0.009 & 0.6 & $N$-acetyltransferase \\
\hline
\end{tabular}

${ }^{\mathrm{a}}$ Values $>0.042=90$ th percentile. 
to transport LIV amino acids and GABA in $R$. leguminosarum (Lodwig et al. 2003; Prell et al. 2010). These data are consistent with observations that rhizobia receive amino acids and GABA from plants (Udvardi and Poole 2013) and are also consistent with the increase of GabT (Fig. 3).
In $R$. leguminosarum, the biosynthesis of LIV amino acids presumably decreases during symbiosis in peas compared with in vitro culture, a likely consequence of suppressed gene expression and reduced enzyme activity (Prell et al. 2009b). That and the dependence on a functional Bra/Aap system for LIV

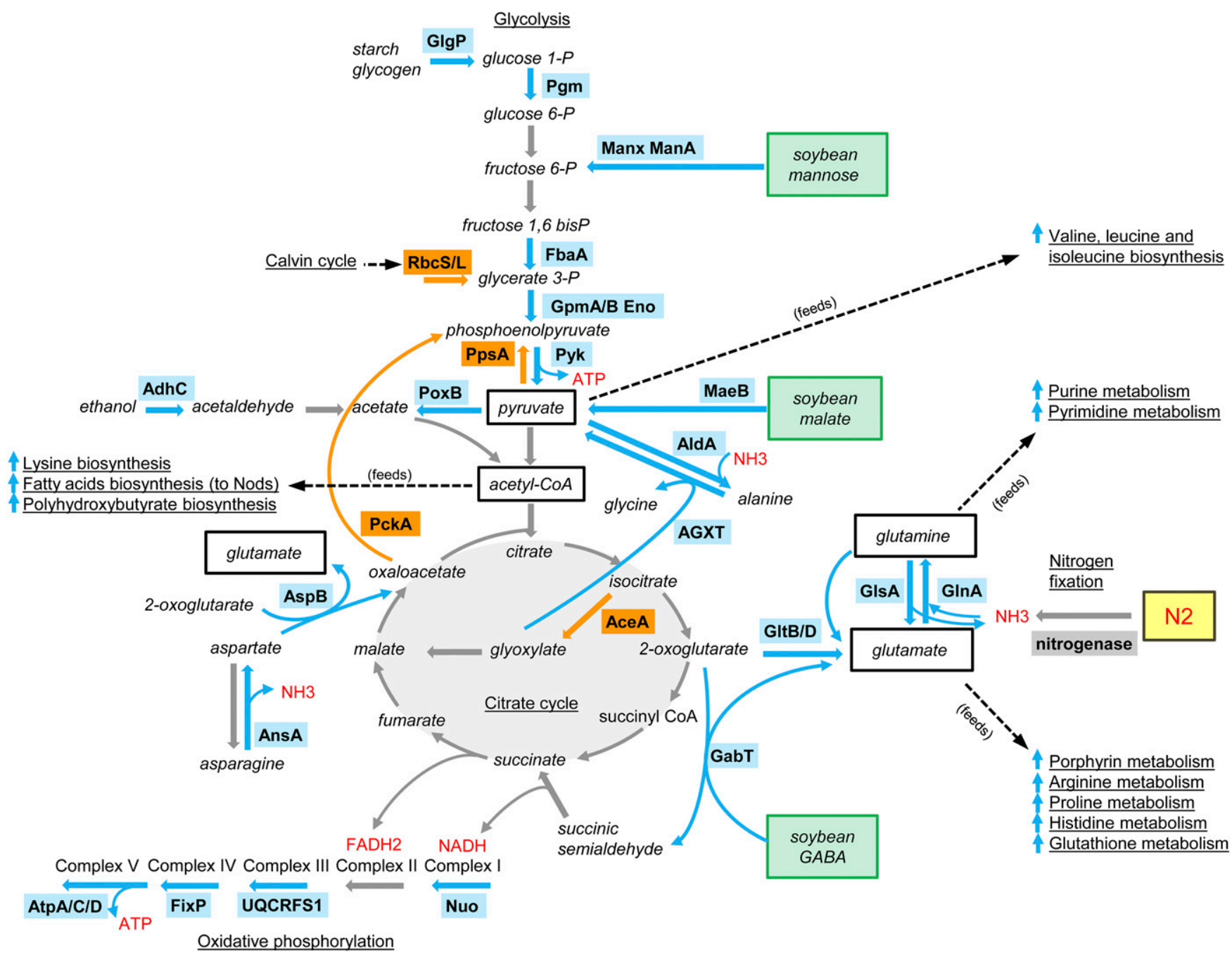

Fig. 3. Carbon and nitrogen assimilation pathways in Bradyrhizobium elkanii USDA 76 (Be76) bacteroids. Enzymes with increased accumulation in Be76 from Peking are denoted with blue arrows and are highlighted in blue. Enzymes with decreased accumulation in Be76 from Peking are denoted with orange arrows and are highlighted in orange. Gray arrows show pathways catalyzed by enzymes not found to have statistically different accumulation changes between Be76 from Peking and Glycine max cv. Williams 82 (W82). Major biochemical pathways are underlined and associated blue arrows indicate that enzymes in these pathways have increased accumulation in Be76 from Peking. AceA $=$ isocitrate lyase, $\mathrm{AdhC}=$ alcohol dehydrogenase, $\mathrm{ALDH}=$ aldehyde dehydrogenase, AnsA $=$ asparaginase, $\mathrm{AspB}=$ aspartate aminotransferase, AtpA/C/D = F-type H+-transporting ATPase, $\mathrm{AGXT}=$ alanine-glyoxylate transaminase, Eno $=$ enolase, $\mathrm{FbaA}=$ fructose bisphosphate aldolase, FixP $=\mathrm{Cbb} 3$-type cytochrome $\mathrm{c}$ oxidase, GabT = gamma aminobutyric acid oxoglutarate aminotransferase, $\mathrm{GlgP}=$ glycogen phosphorylase, $\mathrm{Gln} \mathrm{A}=$ glutamine synthetase, $\mathrm{GlsA}=$ glutaminase, $\mathrm{GltB} / \mathrm{D}=$ glutamate synthase, $\mathrm{GpmA} / \mathrm{B}=$ phosphglyceromutase, $\mathrm{MaeB}=$ malic enzyme, ManA = mannose-6-phosphate isomerase, $\mathrm{ManX}=$ phosphotransferase system mannose IIA component, Nuo = NADH dehydrogenase, PckA = phosphoenolpyruvate carboykinase, $\mathrm{Pgm}=$ phosphoglucomutase, $\mathrm{PpsA}=$ phosphoenolpyruvate synthase, $\mathrm{PoxB}=$ pyruvate dehydrogenase, Pyk $=$ pyruvate kinase, $\mathrm{RbcS} / \mathrm{L}=$ Rubisco, UQCRFS1 = ubiquinol-cytochrome c reductase iron-sulfur subunit.

Table 2. Accumulation change (Peking/Glycine max cv. Williams 82 [W82]) and normalized spectral abundance factors (NSAF) of Bradyrhizobium elkanii USDA 76 (Be76) proteins for $\mathrm{O}_{2}$ sensing and $\mathrm{N}_{2}$ fixation signaling and transcription regulation

\begin{tabular}{lccc}
\hline Record & NSAF $^{\mathbf{a}}$ & $\mathbf{L o g}_{\mathbf{2}}$ fold change & \multicolumn{1}{c}{ Annotation } \\
\hline WP_018269422.1 & 0.029 & 1.0 & $37 \%$ identity FixJ \\
WP_018273613.1 & 0.018 & 0.6 & $50 \%$ identity FixJ \\
WP_018272413.1 & 0.003 & 1.1 & FixJ family \\
WP_018272878.1 & 0.004 & 1.4 & FixJ family \\
WP_016843891.1 & 0.032 & 1.1 & FixH family \\
WP_018269164.1 & 0.007 & 1.3 & RegA-related \\
WP_016847231.1 & 0.008 & 0.8 & Crp/Fnr family transcriptional regulator \\
\hline
\end{tabular}

\footnotetext{
${ }^{a}$ Values $>0.042=90$ th percentile.
} 
uptake support the theory that bacteroids are auxotrophic for LIV (Prell et al. 2009b). But not all symbiotic bacteroids are necessarily auxotrophic for LIV (Prell et al. 2010). This may be true here because, in Be76 from Peking, there were increased amounts of enzymes for the synthesis of 16 amino acids including LIV and glutamine (Fig. 4; Supplementary Fig. S4). Thus, our findings imply that Be76 bacteroids are not necessarily auxotrophic for amino acids, mainly because they have increased amounts of enzymes to produce amino acids in Peking. Despite this, Be76 bacteroids may acquire soybean amino acids through Bra/Aap for some other purpose. Pathway analysis revealed that Be76 from Peking had increased amounts of enzymes leading to amino acid metabolism and degradation, which would lead to the production of acetyl CoA, pyruvate, glutathione, glyoxylate, purines, and pyrimidines and the recycling of sulfur and $\mathrm{NH}_{3}$. Hence, Be76 has proteins to receive amino acids that may serve as signals to maintain symbiosis or serve as a $\mathrm{C}$ source. In addition, $\mathrm{Be} 76$ has the enzymatic capacity to recycle amino acids for efficient $\mathrm{C}$ and $\mathrm{NH}_{3}$ utilization.

\section{$\mathrm{NH}_{3}$ assimilation.}

$\mathrm{NH}_{3}$ is the earliest product of $\mathrm{N}_{2}$ fixation in soybean root nodules and in B. japonicum bacteroids, and this is true for other legumes and their associated rhizobial bacteroids as well (Aprison et al. 1954; Bergersen 1965; Bergersen and Turner 1967). Despite the inherent requirement of bacteroids for fixed $\mathrm{N}_{2}$, a prevailing theory is that bacteroids avoid assimilating the $\mathrm{NH}_{3}$ they produce (Downie 2014; Patriarca et al. 2002; Udvardi and Poole 2013). This is based on the observation that some free-living rhizobia readily assimilate $\mathrm{NH}_{3}$ through the anabolism of glutamine from glutamate but then appear to switch off rhizobial glutamine synthetase $(\mathrm{Gln} A)$ when they become symbiotic bacteroids, prompting the hypothesis that bacteroids become dependent on the plant for assimilated $\mathrm{NH}_{3}$ (Downie 2014). This would create a cycle of nitrogen that is fixed in the bacteroid, assimilated in the plant, and returned to the bacteroid as amino acids, peptides, or dicarboxylates. Our results, however, revealed that Be76 from Peking had increased amounts of four isoforms of GlnA, two of which were among the most highly abundant proteins detected, and they also had increased amounts of GltB/D required to complete the $\mathrm{NH}_{3}$ assimilation cycle (Table 4; Fig. 3; Supplementary Fig. S5). Adenylated (phosphoadenosine) tyrosine/threonine was not detected on GlnA peptides, which spanned nearly $50 \%$ of the two most abundant isoforms, meaning that GlnA was not likely posttranslationally deregulated (Patriarca et al. 2002). Thus, Be76 is enzymatically capable of assimilating $\mathrm{NH}_{3}$ itself, a finding consistent with classical experiments showing that bacteroid glutamate is the primary destination for fixed ${ }^{15} \mathrm{~N}_{2}$ after 5 min of exposure (Ohyama and Kumazawa 1980) and that assimilated $\mathrm{NH}_{3}$ comprises 5 to $16 \%$ of fixed ${ }^{15} \mathrm{~N}_{2}$ in bacteroids (Bergersen and Turner 1990). Furthermore, Be76 in Peking had increased amounts of alanine dehydrogenase that assimilates $\mathrm{NH}_{3}$ in the formation of alanine (although a highly abundant isoform also decreased). $\mathrm{NH}_{3}$ assimilation also was likely facilitated through increased amounts of asparaginase and aspartate aminotransferase (in the aspartate/asparagine cycle) leading to the production of glutamate. These observations can explain ${ }^{15} \mathrm{~N}_{2}$ labeling experiments revealing aspartate and alanine as secondary destinations for assimilated $\mathrm{NH}_{3}$ in bacteroids (Ohyama and Kumazawa 1980) (Table 4; Fig. 3). Pathway analysis revealed that the bacteroid had other proteins that allowed it to continue to metabolize assimilated $\mathrm{NH}_{3}$ through purine, pyrimidine, heme, and glutathione pathways. These pathways are crucial to sustain bacteroid growth, cell division, and symbiosis. Hence, based on the great abundance of enzymes that govern $\mathrm{NH}_{3}$ assimilation and the supporting historical metabolic evidence, it does not appear that Be76 avoids $\mathrm{NH}_{3}$ assimilation at all. Consequently, these data and historical metabolic observations dispel the corollary hypothesis that amino acids received by mature bacteroids are a required source of nitrogen (Udvardi and Poole 2013), at least for Be76 in Peking.

The capacity for bacteroid $\mathrm{NH}_{3}$ assimilation notwithstanding, the traditional model for soybean is that $\mathrm{NH}_{3}$ is mostly

Table 3. Accumulation change (Peking/Glycine max cv. Williams 82 [W82]) and normalized spectral abundance factors (NSAF) abundance of Bradyrhizobium elkanii USDA 76 (Be76) and soybean proteins for amino acid transport

\begin{tabular}{|c|c|c|c|}
\hline Record & NSAF $^{\mathbf{a}}$ & $\log _{2}$ fold change & Annotation \\
\hline WP_018273446.1 & 0.027 & 2.0 & Methionine-binding protein; metQ \\
\hline WP_016840162.1 & 0.018 & 1.9 & Methionine-binding protein; metQ \\
\hline WP_018273085.1 & 0.005 & 1.8 & Leucine-specific binding protein \\
\hline WP_016840105.1 & 0.016 & 1.3 & Methionine-binding protein; metQ \\
\hline WP_018271255.1 & 0.021 & 1.2 & $41 \%$ identity $\mathrm{BraG}$ \\
\hline WP_018270525.1 & 0.007 & 1.2 & $48 \%$ identity BraG \\
\hline WP_026193052.1 & 0.013 & 1.1 & $21 \%$ identity BraC \\
\hline WP_018269577.1 & 0.012 & 1.1 & $43 \%$ identity BraG \\
\hline WP_016843131.1 & 0.015 & 1.1 & $68 \%$ identity BraF \\
\hline WP_018269101.1 & 0.005 & 1.1 & $48 \%$ identity BraG \\
\hline WP_016845632.1 & 0.024 & 1.1 & $56 \%$ identity AapP \\
\hline WP_026193121.1 & 0.004 & 1.0 & $48 \%$ identity BraG \\
\hline WP_018271713.1 & 0.028 & 1.0 & $77 \%$ identity AapP \\
\hline WP_026192609.1 & 0.005 & 0.9 & $22 \%$ identity BraC \\
\hline WP_018270555.1 & 0.012 & 0.8 & $\begin{array}{l}\text { ABC transporter substrate-binding protein; } \\
\text { leucine, isoleucine, and valine (LIV) }\end{array}$ \\
\hline WP_016843860.1 & 0.004 & 0.7 & $48 \%$ identity $\mathrm{BraG}$ \\
\hline WP_038373743.1 & 0.040 & 0.7 & ABC transporter permease; LIV \\
\hline WP_018271220.1 & 0.005 & 0.7 & $29 \%$ identity BraG \\
\hline WP_018272650.1 & 0.004 & 0.6 & $39 \%$ identity BraG \\
\hline WP_026192486.1 & 0.050 & 0.5 & $22 \%$ identity BraC \\
\hline WP_016839818.1 & 0.038 & 0.5 & $25 \%$ identity AapJ \\
\hline WP_018269075.1 & 0.014 & 0.4 & $\mathrm{ABC}$ transporter substrate-binding protein \\
\hline WP_018268989.1 & 0.015 & 0.3 & $24 \%$ identity $\mathrm{BraC}$ \\
\hline WP_018270784.1 & 0.021 & 0.3 & $\begin{array}{l}\text { ABC transporter substrate-binding protein; } \\
\text { LIV }\end{array}$ \\
\hline
\end{tabular}

\footnotetext{
${ }^{\text {a }}$ Values $>0.042=90$ th percentile.
} 
excreted from the bacteroid and assimilated into glutamine in nodules by soybean glutamine synthetase (Smith and Atkins 2002). Soybean glutamine then enters the soybean purine pathway that leads to the production of xanthine, which is converted to uric acid by xanthine dehydrogenase. Uricase then converts uric acid to allantoin, which is converted by allantoinase to allantoic acid, a major transport molecule for assimilated fixed $\mathrm{N}_{2}$ in soybean (Smith and Atkins 2002). Parallel proteomic investigation was performed on Peking and W82 lysed root nodules rinsed of bacteroids, to assess differences in enzyme amounts between the two cultivars. Soybean proteins comprised $80 \%$ of the NSAF totals in these separate experiments. Analysis revealed that one highly abundant glutamine synthetase isoform and one lesser-abundant isoform had increased accumulation in Peking but that these changes were offset by another highly abundant glutamine synthetase isoform with decreased accumulation (Table 4). Notwithstanding, there were no other significant changes in accumulation of eight other soybean glutamine synthetase isoforms or five soybean isoforms of glutamate synthase, nor were there significant accumulation changes for three asparagine synthases, six aspartate aminotransferases, one xanthine dehydrogenase, two uricases, or two allantoinase isoforms in soybean. By contrast, as we showed above, there
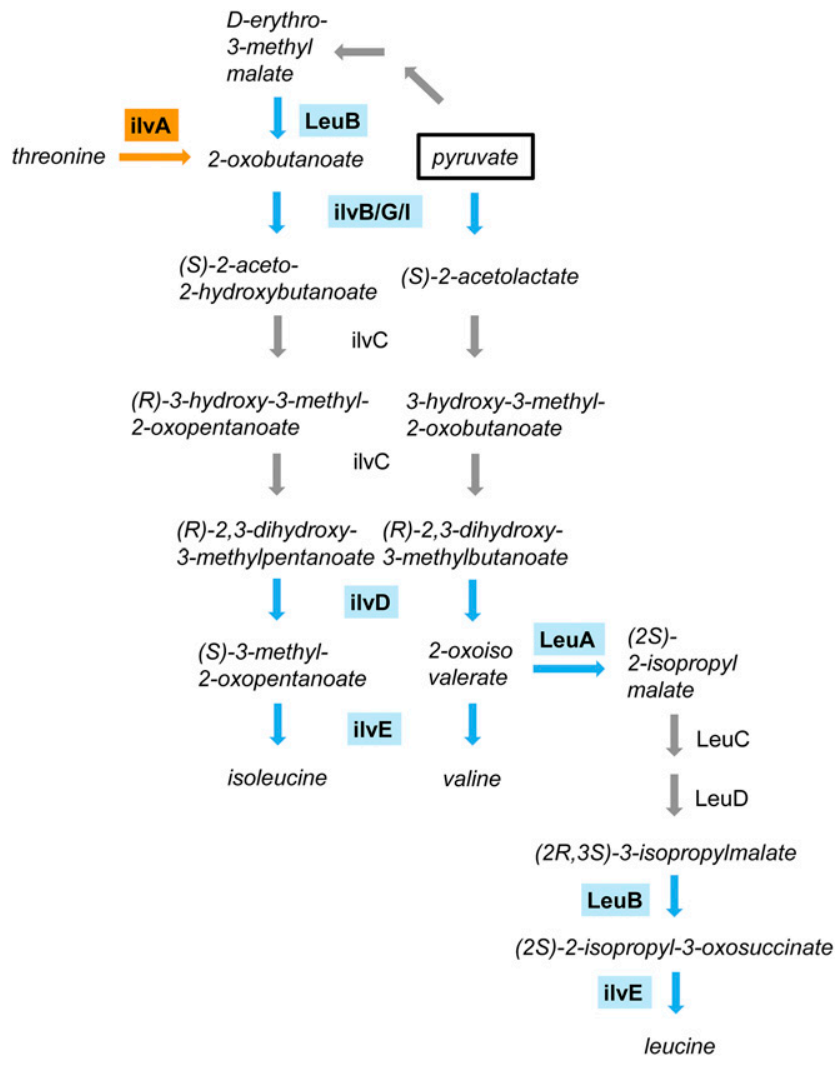

Fig. 4. LIV (leucine, isoleucine, and valine) amino acid biosynthesis pathway in Bradyrhizobium elkanii USDA 76 (Be76). Enzymes with increased accumulation in Be76 from Peking are denoted with blue arrows and are highlighted in blue. Enzymes with decreased accumulation in Be76 from Peking are denoted with orange arrows and are highlighted in orange. Gray arrows show pathways catalyzed by enzymes not found to have statistically different accumulation changes between Be76 from Peking and Glycine $\max \mathrm{cv}$. Williams 82 (W82). IlvA = threonine dehydratase, IlvB/G/I = acetolactate synthase, IlvC $=$ ketol-acid reductoisomerase, IlvD $=$ dihydroxy-acid dehydratase, $\mathrm{IlvE}=$ branched chain amino acid aminotransferase, LeuA $=2$-isopropylmalate synthase, LeuB $=3$-isopropylmalate dehydrogenase, LeuC $=3$-isopropylmalate/(R)-2-methylmalate dehydratase large subunit, LeuD = 3-isopropylmalate/(R)-2-methylmalate dehydratase small subunit. were increased amounts of four GlnA isoforms and other enzymes aiding $\mathrm{NH}_{3}$ assimilation in Be76 bacteroids from Peking, and there were also increased amounts of five Be76 isoforms of xanthine dehydrogenase (Table 4). Be76 uricase was not detected in purified bacteroids. These results suggest that $\mathrm{N}_{2}$ fixation efficiency in Peking may be a result of increased amounts of $\mathrm{NH}_{3}$ assimilation from glutamine through uric acid in the bacteroids, not the soybean cells.

The preceding data suggest the possibility that glutamate/ glutamine, uric acid, or other nitrogen-bearing molecules may be transported from Be76 to Peking. Transport of nitrogen-bearing molecules may be facilitated by some of the transport proteins already mentioned or by 37 others also found with increased accumulation in Be76 from Peking. Several were highly abundant. In addition to nitrogenous molecules like glutathione and urea that could move in and out of Be76 through these channels, small molecules like phosphate and other signaling molecules may be actively transported. Although the canonic ammonium transporter did not show significant change in accumulation, an observation consistent with other systems (Patriarca et al. 2002), it is clear by the numbers and variety of substrate binding and transport proteins found that molecular movement in and out of Be76 may be important to an efficient $\mathrm{N}_{2}$-fixing symbiotic relationship with soybean.

\section{DISCUSSION}

We have demonstrated that $G$. $\max$ cv. Peking grows better in symbiosis with Be76 than does W82, a parent of commercial soybeans grown in the United States. By analyzing $44 \%$ of the proteins encoded by the genome of Be76 bacteroids, a feat made possible by distinguishing bacterial and plant proteins by mass spectrometry, we conclude that symbiotic $\mathrm{N}_{2}$ fixation efficiency is associated with increased amounts of Be76 enzymes that coordinate Nod factor production, porphyrin biosynthesis, $\mathrm{NH}_{3}$ assimilation, ATP production, amino acid metabolism, and purine metabolism as well as being associated with increased amounts of proteins needed to exchange molecules with soybean cells.

The mass spectrometry data reveal that $\mathrm{Be} 76$ bacteroids have increased amounts of enzymes to synthesize amino acids and to assimilate $\mathrm{NH}_{3}$ during efficient symbiosis. These findings are different than what has been observed for taxonomically distinct $R$. leguminosarum and Sinorhizobium meliloti that form indeterminate nodules on peas and Medicago, respectively, as opposed to determinate nodules formed by Be76 on soybean (Terpolilli et al. 2012). R. leguminosarum and S. meliloti are different than Be76 because they have decreased expression for amino acid synthesis genes in bacteroids versus free culture (Capela et al. 2006; Prell et al. 2009b) and because they cease $\mathrm{NH}_{3}$ assimilation as part of a fundamental step in bacteroid development (Patriarca et al. 2002). Furthermore, R. leguminosarum and $S$. meliloti are also unlike Be76 because they do not produce homocitrate, a component of the nitrogenase cofactor that must be acquired from the plant (Terpolilli et al. 2012) and because they do not photosynthesize as free-living organisms (Agarwal and Keister 1983). Consequently, our results do not necessarily contradict prior models for pure cultures or symbioses in Medicago and peas. Instead, our results reveal a contrasting model for a significantly different $B$. elkanii species that is enzymatically capable of utilizing multiple $C$ inputs, assimilating its own fixed $\mathrm{N}_{2}$, and synthesizing amino acids during symbiosis.

Our results of increased accumulation for enzymes catalyzing the formation of glutamine and alanine from $\mathrm{NH}_{3}$ in Be76 bacteroids from Peking are consistent with prior observations of bacteroid biosynthesis of glutamine (Shelp et al. 1983) and alanine (Allaway et al. 2000; Waters et al. 1998). Our detection of Be76 enzymes that make uric acid and its precursors also is 
consistent with high enzymatic activity for purine synthesis in cowpea nodule symbiotic cells (Shelp et al. 1983). By contrast, there were no drastic changes in accumulations of soybean enzymes to assimilate $\mathrm{NH}_{3}$ into glutamine and uric acid that better explain $\mathrm{N}_{2}$ fixation efficiency in Peking. Hence, our findings do not support the theory that soybean exclusively assimilates $\mathrm{NH}_{3}$ into glutamine and converts it to uric acid, a precursor to ureides. Instead, complementary bacteroid enzymes likely contribute to the biochemistry of $\mathrm{N}_{2}$ fixation efficiency in soybean.

At this time, it is not known if any one of these Be 76 proteins uniquely contributes to greater $\mathrm{N}_{2}$ fixation efficiency in Peking. Given the functional redundancy of many of these proteins and the interconnection of the networks in which they function, it is possible that many Be76 proteins are responsible for an enhanced biochemistry in Be76 leading to a net effect of $\mathrm{N}_{2}$ fixation efficiency in Peking. Because there are 36,000 bacteroids per soybean cell per nodule (Bergersen 1997), the enzymatic potential for bacteroid $\mathrm{NH}_{3}$ assimilation is large. With the completion of the genomes for soybean, Be76, and many other rhizobia (Reeve et al. 2017; Schmutz et al. 2010; Seshadri et al. 2015), it is now possible to use mass spectrometry to follow the precise flow of isotopic nitrogen into individual proteins in bacteroids and into soybeans.

\section{MATERIALS AND METHODS}

\section{Rhizobium and nodulation.}

Be76 is a specimen of the USDA-ARS National Rhizobium Germplasm Resource Collection (Reeve et al. 2017). Surfacesterilized seeds for Glycine max cv. Peking and W82 were planted in a 50/50 mixture of sterile sand and potting mix (vermiculite, perlite, and low-nitrogen peat) in Leonard jars. The radicals were inoculated with a liquid suspension of Be76. As a control, some plants received no inoculum. The plants were grown in a chamber at $24^{\circ} \mathrm{C}$ with $12 \mathrm{~h}$ day/night light cycles. The plants were watered with distilled water but received no supplemental nitrogen fertilizer or other nutrients. After 6 weeks, nodules were collected from roots. Multilocus sequencing validated that nodules were only occupied by Be76 (van Berkum et al. 2012).

\section{Bacteroid isolation and protein purification.}

Nodules $(5 \mathrm{~g})$ were ground with a mortar and pestle in $125 \mathrm{mM}$ $\mathrm{KCl}, 50 \mathrm{~m} M$ succinic acid, and $10 \mathrm{~m} M$ potassium phosphate buffer $\mathrm{pH}$ 7.0. The slurry was passed through $100 \mu \mathrm{m}$ and $10 \mu \mathrm{m}$ filters, each washed three times in grinding buffer. The filtrate was passed through a $0.45 \mu \mathrm{m}$ membrane, and the flow-through was collected. The membrane was washed 3 times then inverted, and cells were washed off and combined with the prior flowthrough. Cells were concentrated and ruptured with dilute chloroform (Ames et al. 1984). Protein was precipitated in acetone and trichloroacetic acid. Proteins $(\sim 300 \mu \mathrm{g})$ were reduced in Tris (2-carboxyethyl) phosphine, carboxyamidomethylated with iodoacetamide, and digested overnight at $37^{\circ} \mathrm{C}$ with trypsin. The digested peptides were purified by reverse phase chromatography.

\section{Quantitative mass spectrometry.}

Equal amounts of peptides $(75 \mu \mathrm{g})$ from three biological replicate experiments were prepared for 6-plex TMT labeling and quantitative mass spectrometry at the Thermo Fisher Center for Multiplexed Proteomics at Harvard University as previously described (Isasa et al. 2015). Samples were analyzed to determine TMT label incorporation percentage $(>99 \%)$ and to estimate quantitative ratios between samples. On the basis of the quantitative ratios, labeled samples were mixed together 1:1:1:1: $1: 1$ and fractionated by high-pH reverse phase HPLC (Isasa et al. 2015). Twelve concatenated fractions were analyzed using a multinotch $\mathrm{MS}^{3}$ method using settings previously described (McAlister et al. 2014). Sequest HT in Proteome Discoverer 2.1 was used to match tandem mass spectra to soybean (G. max Wm82.a2.v11; 56,044 records; (Schmutz et al. 2010)) and Be76 (Bradyelkanii76_ASM37914v1; 8,362 records; (Reeve et al. 2017)) reference protein sequences and their reverse complements. Search parameters were for tryptic digests with two possible missed cleavages, fixed amino acid modification for chemically modified cysteine and TMT-labeled N-terminal and internal lysine $(+57.021 \mathrm{Da}, \mathrm{C}$; +229.163 Da, K), variable oxidized methionine (+15.995 Da, M), monoisotopic mass values, $\pm 10 \mathrm{ppm}$ parent ion mass tolerance, and $\pm 0.6 \mathrm{Da}$ fragment ion mass tolerance. Peptide-spectrum matches (PSM) were processed by Percolator (Käll et al. 2007) using settings for delta Cn $(0.05)$, decoy-estimated false discovery rate $(0.01)$, and posteriorerror probability (0.01). Additional filters limited Sequest PSM Xcorr for $+1,+2,+3, \geq+4$ parent ions $(1.2 ; 1.9 ; 2.3 ; 2.6)$. Peptides were assigned to logical protein groups using parsimony. Proteins were quantified on summed signal-to-noise $(\mathrm{S} / \mathrm{N})$ ratios for each TMT channel for qualified PSMs for unique peptides. The most

Table 4. Accumulation change (Peking/Glycine max cv. Williams 82 [W82]) and normalized spectral abundance factors (NSAF) abundance of Bradyrhizobium elkanii USDA 76 (Be76) and soybean proteins for $\mathrm{NH}_{3}$ assimilation

\begin{tabular}{llcc}
\hline Record & NSAF & Log $_{2}$ fold change & Annotation \\
\hline WP_016841105.1 & $0.042^{\mathrm{a}}$ & 1.4 & Glutamine synthetase GlnA \\
WP_026193105.1 & $0.013^{\mathrm{a}}$ & 0.9 & Glutamine synthetase GlnA \\
WP_018271875.1 & $0.098^{\mathrm{a}}$ & 0.6 & Glutamine synthetase GlnA \\
WP_016841591.1 & $0.008^{\mathrm{a}}$ & 1.0 & Glutamine synthetase GlnA \\
WP_011441447.1 & $0.056^{\mathrm{a}}$ & 0.7 & Nitrogen regulatory protein P-II, GlnB \\
WP_018269709.1 & $0.072^{\mathrm{a}}$ & 0.5 & Glutamate synthase GltB \\
WP_018269708.1 & $0.076^{\mathrm{a}}$ & 0.6 & Glutamate synthase GltD \\
WP_016846966.1 & $0.058^{\mathrm{a}}$ & 0.8 & Asparaginase AnsA \\
WP_018271003.1 & $0.020^{\mathrm{a}}$ & 0.8 & Aspartate aminotransferase AspB \\
WP_018269904.1 & $0.032^{\mathrm{a}}$ & 0.6 & Alanine dehydrogenase AldA \\
WP_016847652.1 & $0.163^{\mathrm{a}}$ & -0.4 & Alanine dehydrogenase AldA \\
WP_018270367.1 & $0.024^{\mathrm{a}}$ & 1.4 & Xanthine dehydrogenase YagR \\
WP_018270366.1 & $0.021^{\mathrm{a}}$ & 1.4 & Xanthine dehydrogenase YagS \\
WP_016844561.1 & $0.014^{\mathrm{a}}$ & 1.3 & Xanthine dehydrogenase YagT \\
WP_026192949.1 & $0.011^{\mathrm{a}}$ & 1.1 & Xanthine dehydrogenase YagS \\
WP_026192699.1 & $0.001^{\mathrm{a}}$ & 0.9 & Xanthine dehydrogenase \\
Glyma.09G173200.1.p & $0.054^{\mathrm{b}}$ & 1.0 & Soybean glutamine synthetase \\
Glyma.02G243900.1.p & $0.026^{\mathrm{b}}$ & 4.6 & Soybean glutamine synthetase \\
Glyma.18G041100.1.p & $0.063^{\mathrm{b}}$ & -1.0 & Soybean glutamine synthetase1;4 \\
\hline
\end{tabular}

\footnotetext{
${ }^{\text {a }}$ Values $>0.042=90$ th percentile.

${ }^{\mathrm{b}}$ Values $>0.053=90$ th percentile.
} 
confident centroid within $0.003 \mathrm{Da}$ of the expected mass for each reporter ion was used. There were 4,888 proteins quantified from $\mathrm{MS}^{3}$ signals for unique peptides filtered by an average $\mathrm{S} / \mathrm{N}$ threshold $\geq 8$ and isolation specificity of 0.25 . Protein quantitative values were normalized and scaled. A $t$ test was used to determine significantly different quantitative values, and Benjamini and Hochberg correction set the false discovery rate (FDR) to $\leq 0.05$. Proteins quantified with only 1 spectrum were excluded from the final dataset. The numbers of spectra contributing to the identification of all shared and distinct peptides assigned to a protein or logical protein group were summed using a previously validated model (Cooper et al. 2010). NSAFs were calculated to estimate the relative abundance of each protein to all others (Paoletti et al. 2006). Protein sequences were compared with Swiss-Prot (downloaded 03/18/2016) with BLASTP. KEGG identifiers were assigned with the $B$. japonicum USDA 110 reference and mapped to biochemical pathways (www.kegg.jp). Mass spectrometry data are archived at https://figshare.com/s/f05115faf61ef8deceff.

Proteins from residual soybean nodule materials separated from the bacteroids from three biological experiments were analyzed separately at the United States Department of Agriculture Agricultural Research Service in Beltsville, Maryland, using procedures and settings mirroring those used to analyze bacteroids. TMT-labeled peptides were fractionated with the Pierce high $\mathrm{pH}$ reversed-phase peptide fractionation kit (Thermo Fisher Scientific). Peptides (approximately $500 \mathrm{ng}$ per fraction) were separated on a 75- $\mu \mathrm{m}$ (inner diameter) fused silica capillary emitter packed with $22 \mathrm{~cm}$ of 2.5-micron Synergi Hydro-RP C18 (Phenomenex), coupled directly to a Dionex UltiMate 3000 RSLC nano system (Thermo Fisher Scientific) controlling a 180-min linear gradient from 3.2 to $40 \%$ acetonitrile and $0.1 \%$ formic acid, at a flow rate of $300 \mathrm{nl}$ per minute. Peptides were electrosprayed at $2.4 \mathrm{kV}$ into an Orbitrap Fusion Lumos Tribrid mass spectrometer (Thermo Fisher Scientific) operating in data-dependent mode with positive polarity and using $445.12003 \mathrm{~m} / \mathrm{z}$ as an internal mass calibrant. Quadrupole isolation was enabled and survey scans were recorded in the Orbitrap at 120,000 resolution over a mass range of 400 to $1,600 \mathrm{~m} / \mathrm{z}$. The instrument was operated in Top Speed mode, using the multinotch $\mathrm{MS}^{3}$ method with a cycle time of $3 \mathrm{~s}$. The automatic gain control (AGC) target was set to 200,000 and the maximum injection time was set to 50 milliseconds (ms). The most abundant precursor ions (intensity threshold 5,000) were fragmented by collision-induced dissociation ( $35 \%$ energy) and fragment ions were detected in the linear ion trap (AGC 10,000, 50 ms maximum injection). Analyzed precursors were dynamically excluded for $45 \mathrm{~s}$. Multiple $\mathrm{MS}^{2}$ fragment ions were captured using isolation waveforms with multiple frequency notches and were fragmented by high energy collision-induced dissociation (65\% normalized collision energy). $\mathrm{MS}^{3}$ spectra were acquired in the Orbitrap (AGC 100,000; maximum injection time $120 \mathrm{~ms}, 60,000$ resolution scanning from 100 to $500 \mathrm{~m} / \mathrm{z}$ ). PSMs were assessed as described above, and 3,054 soybean proteins were quantified.

\section{ACKNOWLEDGMENTS}

We thank J.W. Cooper for collecting root nodules and M. Udvardi at the Noble Research Institute for his helpful critique. This research was funded entirely by the United States Department of Agriculture Agricultural Research Service.

\section{LITERATURE CITED}

Agarwal, A. K., and Keister, D. L. 1983. Physiology of ex planta nitrogenase activity in Rhizobium japonicum. Appl. Environ. Microbiol. 45:1592-1601.

Allaway, D., Lodwig, E. M., Crompton, L. A., Wood, M., Parsons, R., Wheeler, T. R., and Poole, P. S. 2000. Identification of alanine dehydrogenase and its role in mixed secretion of ammonium and alanine by pea bacteroids. Mol. Microbiol. 36:508-515.
Ames, G. F., Prody, C., and Kustu, S. 1984. Simple, rapid, and quantitative release of periplasmic proteins by chloroform. J. Bacteriol. 160:1181-1183.

Aprison, M. H., Magee, W. E., and Burris, R. H. 1954. Nitrogen fixation by excised soy bean root nodules. J. Biol. Chem. 208:29-39.

Bergersen, F. J. 1965. Ammonia-An early stable product of nitrogen fixation by soybean root nodules. Aust. J. Biol. Sci. 18:1-9.

Bergersen, F. J. 1997. Physiological and biochemical aspects of nitrogen fixation by bacteroids in soybean nodule cells. Soil Biol. Biochem. 29:875-880.

Bergersen, F. J., and Turner, G. L. 1990. Bacteroids from soybean root nodules: Respiration and $\mathrm{N}_{2}$-fixation in flow-chamber reactions with oxyleghaemoglobin. Proc. R. Soc. Lond., B 238:295-320.

Bergersen, J. F., and Turner, G. L. 1967. Nitrogen fixation by the bacteroid fraction of breis of soybean root nodules. Biochim. Biophys. Acta 141: 507-515.

Bobik, C., Meilhoc, E., and Batut, J. 2006. FixJ: A major regulator of the oxygen limitation response and late symbiotic functions of Sinorhizobium meliloti. J. Bacteriol. 188:4890-4902.

Capela, D., Filipe, C., Bobik, C., Batut, J., and Bruand, C. 2006. Sinorhizobium meliloti differentiation during symbiosis with alfalfa: A transcriptomic dissection. Mol. Plant-Microbe Interact. 19:363-372.

Cooper, B., Feng, J., and Garrett, W. M. 2010. Relative, label-free protein quantitation: Spectral counting error statistics from nine replicate MudPIT samples. J. Am. Soc. Mass Spectrom. 21:1534-1546.

Dao, T. V., Nomura, M., Hamaguchi, R., Kato, K., Itakura, M., Minamisawa, K., Sinsuwongwat, S., Le, H. T., Kaneko, T., Tabata, S., and Tajima, S. 2008. NAD-malic enzyme affects nitrogen fixing activity of Bradyrhizobium japonicum USDA 110 bacteroids in soybean nodules. Microbes Environ. 23:215-220.

Dénarié, J., Debellé, F., and Promé, J. C. 1996. Rhizobium lipochitooligosaccharide nodulation factors: signaling molecules mediating recognition and morphogenesis. Annu. Rev. Biochem. 65:503-535.

Downie, J.A. 2014. Legume nodulation. Curr. Biol. 24:R184-R190.

Farkas, A., Maróti, G., Durgő, H., Györgypál, Z., Lima, R. M., Medzihradszky, K. F., Kereszt, A., Mergaert, P., and Kondorosi, É. 2014. Medicago truncatula symbiotic peptide NCR247 contributes to bacteroid differentiation through multiple mechanisms. Proc. Natl. Acad. Sci. U.S.A. 111: 5183-5188.

Glenn, A. R., and Dilworth, M. J. 1981. Oxidation of substrates by isolated bacteroids and free-living cells of Rhizobium leguminosarum 3841. J. Gen. Microbiol. 126:243-247.

Hirsch, A. M., and Smith, C. A. 1987. Effects of Rhizobium meliloti nif and fix mutants on alfalfa root nodule development. J. Bacteriol. 169: 1137-1146.

Hu, Y., Fay, A. W., Lee, C. C., Yoshizawa, J., and Ribbe, M. W. 2008 Assembly of nitrogenase MoFe protein. Biochemistry 47:3973-3981.

Isasa, M., Rose, C. M., Elsasser, S., Navarrete-Perea, J., Paulo, J. A., Finley, D. J., and Gygi, S. P. 2015. Multiplexed, proteome-wide protein expression profiling: Yeast deubiquitylating enzyme knockout strains. J. Proteome Res. 14:5306-5317.

Käll, L., Canterbury, J. D., Weston, J., Noble, W. S., and MacCoss, M. J. 2007. Semi-supervised learning for peptide identification from shotgun proteomics datasets. Nat. Methods 4:923-925.

Lodwig, E. M., Hosie, A. H., Bourdès, A., Findlay, K., Allaway, D., Karunakaran, R., Downie, J. A., and Poole, P. S. 2003. Amino-acid cycling drives nitrogen fixation in the legume-Rhizobium symbiosis. Nature 422:722-726.

Mao, Y. H., Li, F., Ma, J. C., Hu, Z., and Wang, H. H. 2016. Sinorhizobium meliloti functionally replaces 3-oxoacyl-acyl carrier protein reductase (FabG) by overexpressing NodG during fatty acid synthesis. Mol. PlantMicrobe Interact. 29:458-467.

McAlister, G. C., Nusinow, D. P., Jedrychowski, M. P., Wühr, M., Huttlin, E. L., Erickson, B. K., Rad, R., Haas, W., and Gygi, S. P. 2014 MultiNotch MS3 enables accurate, sensitive, and multiplexed detection of differential expression across cancer cell line proteomes. Anal. Chem. 86:7150-7158.

Mesa, S., Reutimann, L., Fischer, H. M., and Hennecke, H. 2009. Posttranslational control of transcription factor FixK2, a key regulator for the Bradyrhizobium japonicum-soybean symbiosis. Proc. Natl. Acad. Sci. U.S.A. 106:21860-21865.

Nellen-Anthamatten, D., Rossi, P., Preisig, O., Kullik, I., Babst, M., Fischer, H. M., and Hennecke, H. 1998. Bradyrhizobium japonicum FixK2, a crucial distributor in the FixLJ-dependent regulatory cascade for control of genes inducible by low oxygen levels. J. Bacteriol. 180:5251-5255.

Ohyama, T., and Kumazawa, K. 1980. Nitrogen assimilation in soybean nodules II. ${ }^{15} \mathrm{~N}_{2}$ assimilation in bacteroid and cytosol fractions of soybean nodules. Soil Sci. Plant Nutr. 26:205-213.

Paoletti, A. C., Parmely, T. J., Tomomori-Sato, C., Sato, S., Zhu, D., Conaway, R. C., Conaway, J. W., Florens, L., and Washburn, M. P. 2006. 
Quantitative proteomic analysis of distinct mammalian Mediator complexes using normalized spectral abundance factors. Proc. Natl. Acad. Sci. U.S.A. 103:18928-18933.

Patriarca, E. J., Tatè, R., and Iaccarino, M. 2002. Key role of bacterial $\mathrm{NH}_{4}{ }^{+}$ metabolism in Rhizobium-plant symbiosis. Microbiol. Mol. Biol. Rev. 66: 203-222.

Prell, J., Bourdès, A., Karunakaran, R., Lopez-Gomez, M., and Poole, P. 2009a. Pathway of gamma-aminobutyrate metabolism in Rhizobium leguminosarum 3841 and its role in symbiosis. J. Bacteriol. 191: 2177-2186.

Prell, J., Bourdès, A., Kumar, S., Lodwig, E., Hosie, A., Kinghorn, S., White, J., and Poole, P. 2010. Role of symbiotic auxotrophy in the Rhizobium-legume symbioses. PLoS One 5:e13933.

Prell, J., White, J. P., Bourdes, A., Bunnewell, S., Bongaerts, R. J., and Poole, P. S. 2009b. Legumes regulate Rhizobium bacteroid development and persistence by the supply of branched-chain amino acids. Proc. Natl. Acad. Sci. U.S.A. 106:12477-12482.

Price, G. D., Day, D. A., and Gresshoff, P. M. 1987. Rapid isolation of intact peribacteroid envelopes from soybean nodules and demonstration of selective permeability to metabolites. J. Plant Physiol. 130:157-164.

Reeve, W., van Berkum, P., Ardley, J., Tian, R., Gollagher, M., Marinova, D., Elia, P., Reddy, T. B. K., Pillay, M., Varghese, N., Seshadri, R., Ivanova, N., Woyke, T., Baeshen, M. N., Baeshen, N. A., and Kyrpides, N. 2017. Highquality permanent draft genome sequence of the Bradyrhizobium elkanii type strain USDA 76(T), isolated from Glycine max (L.) Merr. Stand. Genomic Sci. 12:26.

Reid, C. J., and Poole, P. S. 1998. Roles of DctA and DctB in signal detection by the dicarboxylic acid transport system of Rhizobium leguminosarum. J. Bacteriol. 180:2660-2669.

Ruiz-Argüeso, T., Emerich, D. W., and Evans, H. J. 1979. Characteristics of the $\mathrm{H}_{2}$ oxidizing system in soybean nodule bacteroids. Arch. Microbiol. 121:199-206.

Salminen, S. O., and Streeter, J. G. 1987. Involvement of glutamate in the respiratory metabolism of Bradyrhizobium japonicum bacteroids. J. Bacteriol. 169:495-499.

Salminen, S. O., and Streeter, J. G. 1990. Factors contributing to the accumulation of glutamate in Bradyrhizobium japonicum bacteroids under microaerobic conditions. J. Gen. Microbiol. 136:2119-2126.

Schmutz, J., Cannon, S. B., Schlueter, J., Ma, J., Mitros, T., Nelson, W., Hyten, D. L., Song, Q., Thelen, J. J., Cheng, J., Xu, D., Hellsten, U., May, G. D., Yu, Y., Sakurai, T., Umezawa, T., Bhattacharyya, M. K., Sandhu, D., Valliyodan, B., Lindquist, E., Peto, M., Grant, D., Shu, S., Goodstein, D., Barry, K., Futrell-Griggs, M., Abernathy, B., Du, J., Tian, Z., Zhu, L., Gill, N., Joshi, T., Libault, M., Sethuraman, A., Zhang, X. C., Shinozaki, K., Nguyen, H. T., Wing, R. A., Cregan, P., Specht, J., Grimwood, J.,
Rokhsar, D., Stacey, G., Shoemaker, R. C., and Jackson, S. A. 2010. Genome sequence of the palaeopolyploid soybean. Nature 463:178-183.

Sciotti, M. A., Chanfon, A., Hennecke, H., and Fischer, H. M. 2003 Disparate oxygen responsiveness of two regulatory cascades that control expression of symbiotic genes in Bradyrhizobium japonicum. J. Bacteriol. 185:5639-5642.

Seshadri, R., Reeve, W. G., Ardley, J. K., Tennessen, K., Woyke, T., Kyrpides, N. C., and Ivanova, N. N. 2015. Discovery of novel plant interaction determinants from the genomes of 163 root nodule bacteria. Sci. Rep. 5:16825.

Sessitsch, A., Howieson, J. G., Perret, X., Antoun, H., and MartinezRomero, E. 2002. Advances in rhizobium research. Crit. Rev. Plant Sci. 21:323-378.

Shelp, B. J., Atkins, C. A., Storer, P. J., and Canvin, D. T. 1983. Cellular and subcellular organization of pathways of ammonia assimilation and ureide synthesis in nodules of cowpea (Vigna unguiculata L. Walp.). Arch. Biochem. Biophys. 224:429-441.

Smith, P. M., and Atkins, C. A. 2002. Purine biosynthesis. Big in cell division, even bigger in nitrogen assimilation. Plant Physiol. 128:793-802.

Terpolilli, J. J., Hood, G. A., and Poole, P. S. 2012. What determines the efficiency of $\mathrm{N}_{2}$-fixing Rhizobium-legume symbioses? Adv. Microb. Physiol. 60:325-389.

Udvardi, M., and Poole, P. S. 2013. Transport and metabolism in legumerhizobia symbioses. Annu. Rev. Plant Biol. 64:781-805.

Udvardi, M. K., Ou Yang, L. J., Young, S., and Day, D. A. 1990. Sugar and amino acid transport across symbiotic membranes from soybean nodules. Mol. Plant-Microbe Interat. 3:334-340.

Udvardi, M. K., Price, G. D., Gresshoff, P. M., and Day, D. A. 1988. A dicarboxylate transporter on the peribacteroid membrane of soybean nodules. FEBS Lett. 231:36-40.

van Berkum, P., Elia, P., Song, Q., and Eardly, B. D. 2012. Development and application of a multilocus sequence analysis method for the identification of genotypes within genus Bradyrhizobium and for establishing nodule occupancy of soybean (Glycine max L. Merr). Mol. Plant-Microbe Interact. 25:321-330.

Vance, C. P., and Gantt, J. S. 1992. Control of nitrogen and carbon metabolism in root nodules. Physiol. Plant. 85:266-274.

Waters, J. K., Hughes, B. L., 2nd, Purcell, L. C., Gerhardt, K. O., Mawhinney, T. P., and Emerich, D. W. 1998. Alanine, not ammonia, is excreted from $\mathrm{N}_{2}$-fixing soybean nodule bacteroids. Proc. Natl. Acad. Sci. U.S.A. 95:12038-12042.

Wilson, K. J., Anjaiah, V., Nambiar, P. T., and Ausubel, F. M. 1987. Isolation and characterization of symbiotic mutants of bradyrhizobium sp. (Arachis) strain NC92: Mutants with host-specific defects in nodulation and nitrogen fixation. J. Bacteriol. 169:2177-2186. 